\title{
Evolution of Pulse Shortening Research in Narrow Band, High Power Microwave Sources
}

\author{
Forrest J. Agee, Senior Member, IEEE
}

\begin{abstract}
The achievements resulting from the application of advanced pulsed power to the generation of high power microwaves (HPM) have included the generation of multi-gigawatt pulses of RF energy. The power achievable is orders of magnitude greater than conventional microwave sources can generate. However, the introduction of the HPM technology into logical applications has been limited to date due to the phenomenon of pulse shortening in which the RF pulse terminates before the pulse power source used to produce it. Conventional microwave tubes can generate a few to $10 \mathrm{MW}$ of power with pulsewidths of many microseconds when required. High power microwave sources can produce gigawatts of power, but only for relatively short pulsewidths, typically tens to hundreds of nanoseconds. An international effort during the past few years has generated important new discoveries toward the elimination of pulse shortening. Some of the new techniques have the potential for helping the conventional tube industry as well as being practical for high power microwave sources. This paper reviews the pulse shortening problem, its causes, and the worldwide scope and direction of research conducted to date to resolve it. The paper also discusses the potential remedies for the problem and recommends a course of research to further progress on the issue.
\end{abstract}

\section{INTRODUCTION}

D URING the last few years there has been a concerted effort to address the problem of pulse shortening in narrow band high power microwave (HPM) tubes. This phenomenon limits the amount of energy in the radiated pulse due to processes that terminate the RF generation well before the pulsed power source turns off. Because many potential applications seek longer pulses (microseconds) at high power (gigawatts), pulse shortening in these tubes is a concern that has received a lot of attention in the high power source community.

The application of multi-gigawatt pulsed power to the generation of microwave radiation has enabled increases in RF power in HPM by more than three orders of magnitude in peak power. The potential impact of such progress is so great that it could revolutionize certain technologies. Narrowband HPM tubes have achieved power levels in excess of $1 \mathrm{GW}$ in a number of cases, however, the limit to these successes has been the inability to produce long pulses of $\mathrm{RF}$, containing comparable increases in RF energy as well. The phenomenon known as pulse shortening tends to limit the energy in microwave pulses, usually tending to hold the energy

Manuscript received December 20, 1997; revised February 20, 1998.

The author was with the USAF Air Force Research Laboratory, Kirtland AFB, NM 87117 USA. He is now with the Air Force Office of Scientific Research, Bolling AFB, Washington, DC 20332 USA.

Publisher Item Identifier S 0093-3813(98)04293-3. in the pulse more or less constant as power is increased. This has been a widely seen phenomenon, common in one form or another to many different HPM sources using a variety of mechanisms for the RF generation process. Cross-field devices, klystrons, Cerenkov generators, and other tubes have been affected. The problem has been one that has achieved prominence in the U.S. over the past several years, with a focussed multi-laboratory effort of considerable magnitude devoted to the resolution of the problem. Table I presents a partial list of efforts in pulse shortening around the world. The applications that would benefit from its resolution are several, including advanced radar and accelerator applications. The problem of pulse shortening was raised by Russian authors, including Mesyats [1] and Voronkov et al. [2], several years ago. They referred to the problem as limiting energy to $10 \mathrm{~J}$ in Cherenkov generators and to a few hundred joules in oversized systems, with the pulse length of the microwaves being less than the current pulse even at moderate power. Work at the Air Force Research Laboratory was motivated by pulse shortening observed in a number of sources of research interest. A good example of pulse shortening was that seen in the magnetically insulated line oscillator (MILO). As recently as 1995, energy in the MILO was limited in energy to about $50 \mathrm{~J}$ over a power range from $50 \mathrm{MW}$ to $1 \mathrm{GW}$ [3]. Pulse shortening was raised as a research issue in the U.S. at the 1995 IEEE ICOPS meeting and further lively discussions were held regarding the probable causes and possible cures at the Intense Microwave III Conference at the SPIE meeting in San Diego, CA, in 1995 [4]. This had the effect of focusing attention to the problem and galvanizing action in the intervening time. In part, these actions in the U.S. have been as a result of the Air Force Office of Scientific Research (AFOSR) sponsored research program in High Power Microwaves, a Multidisciplinary University Research Initiative (MURI) Program, involving nine universities and the Air Force Research Laboratory [5]. ${ }^{1}$ However, other efforts have also been initiated with some success in industry and elsewhere, and the subject of pulse shortening is now a major topic of HPM research in a number of laboratories worldwide. Table I summarizes the current research efforts in several of these key laboratories. Some progress has been made in increasing the energy in the pulse for a number of sources, including the MILO, as was disclosed in a recent workshop on

\footnotetext{
${ }^{1}$ References to the Digest of Technical Papers, International Workshop on High Power Microwave Generation and Pulse Shortening, Edindurgh, Scotland, U.K., June 10-12, 1997, are available online: http://library,plk.af.mil/edinburgh/digest.html
} 
TABLE I

A Summary of the Work Being Done by Key Laboratories Around the World Conducting Research in the Pulse Shortening Problem SeEn IN Many HPM Sources

\begin{tabular}{|c|c|c|c|c|}
\hline Country & Organization & Location & $\begin{array}{l}\text { HPM Source } \\
\text { Technology }\end{array}$ & $\begin{array}{l}\text { Pulse Lengthening } \\
\text { Strategy (Ref. \#s) }\end{array}$ \\
\hline France & $\begin{array}{l}\text { Thomson-Shorts- } \\
\text { Systemes }\end{array}$ & Velizy & Oversized BWO & $\begin{array}{l}\text { Avoid breakdown and plasma from } \\
\text { walls by using oversized BWO with } \\
\text { internal Bragg mode converter (43) }\end{array}$ \\
\hline $\begin{array}{l}\text { Russia } \\
\text { Res }\end{array}$ & $\begin{array}{l}\text { Radiotechnical } \\
\text { Institute }\end{array}$ & Moscow & $\begin{array}{l}\text { Theory, electron } \\
\text { beam accelerator }\end{array}$ & $\begin{array}{l}\text { Use two-beam cathode formation to } \\
\text { produce fast turn-on current pulses } \\
\text { (50) }\end{array}$ \\
\hline Russia & $\begin{array}{l}\text { General Physics } \\
\text { Institute }\end{array}$ & Moscow & Relativistic BWO & $\begin{array}{l}\text { Eliminate urwanted plasma; use } \\
\text { plasma microwave osciltator to keep } \\
\text { REB away from walls (11) }\end{array}$ \\
\hline Russia & $\begin{array}{l}\text { Institute of High } \\
\text { Current } \\
\text { Electronics }\end{array}$ & Tomsk & Relativistic BWO & $\begin{array}{l}\text { Minimize E-field on SWS with using } \\
\text { resonant reflectors }(42)\end{array}$ \\
\hline Russia & $\begin{array}{l}\text { Instinute of } \\
\text { Applicd Physics }\end{array}$ & $\begin{array}{l}\text { Nizhiny } \\
\text { Novgorod }\end{array}$ & $\begin{array}{l}\text { Relativistic } \\
\text { Carcinotron } \\
\text { (BWO), TWTs }\end{array}$ & $\begin{array}{l}\text { Thermionic injector studies; avoid } \\
\text { plasma at collector and interaction } \\
\text { region; use conventions! baking and } \\
\text { sealing of tubes; study plasma } \\
\text { created during microwave-induced } \\
\text { breakdown on dielectric surfices; } \\
\text { employ oversized BWO systems; } \\
\text { multichannel feedback }(20,48)\end{array}$ \\
\hline Russia & $\begin{array}{l}\text { Institute of } \\
\text { Flectrophysics }\end{array}$ & & $\begin{array}{l}\text { Theory, Pulser/ } \\
\text { diode tester }\end{array}$ & $\begin{array}{l}\text { Treat electrode surface to improve } \\
\text { electric field strength of diode; } \\
\text { experimenta1 investigation of ns and } \\
\text { sub-ns vacuum breakdown in diodes } \\
\text { with electron beams present (15) }\end{array}$ \\
\hline$\overline{\mathrm{UK}}$ & $\begin{array}{l}\text { University of } \\
\text { Strathclyde }\end{array}$ & Glasgow & Gyrotron oscillator & $\begin{array}{l}\text { Explosive cathode studies to } \\
\text { understand effect of cathode } \\
\text { materials, gap spacing and magnetic } \\
\text { feeld on diode impedance collapse } \\
\text { (28) }\end{array}$ \\
\hline$\overline{\mathrm{LK}}$ & DERA & Malvem & Cathode research & $\begin{array}{l}\text { Investigate novel cathode construets } \\
\text { which slow gap closure ( } 71)\end{array}$ \\
\hline$\overline{\mathrm{IKK}}$ & King's College & London: & $\begin{array}{l}\text { Simulation } \\
\text { Of relativistic } \\
\text { magnetron }\end{array}$ & $\begin{array}{l}\text { Slow gap elosure by vacuum } \\
\text { processing anode to reduce ion } \\
\text { formation; bake and seal tube (10) }\end{array}$ \\
\hline$\overline{\text { UK }}$ & AEA Techrology & Oxfordshire & $\begin{array}{l}\text { Tapered MILO, } \\
\text { Relativistic } \\
\text { Marnetron }\end{array}$ & $\begin{array}{l}\text { For magnetron: prevent fall in input } \\
\text { voltage; increasc power flow }(62)\end{array}$ \\
\hline USA & $\begin{array}{l}\text { Stanford Linear } \\
\text { Accelerator } \\
\text { (SLAC) }\end{array}$ & $\begin{array}{l}\text { Stanford } \\
\text { University, } \\
\text { CA }\end{array}$ & $\begin{array}{l}\text { Conventional High } \\
\text { Power Klystrons }\end{array}$ & $\begin{array}{l}\text { Use ceramics, thermionic cathodes; } \\
\text { buke, rf condition tube; attain high } \\
\text { vacuum; Long puise HiPM derived } \\
\text { from MBK using conventional tube } \\
\text { processing techniques }(5:, 52,54)\end{array}$ \\
\hline USA & $\begin{array}{l}\text { Microwave } \\
\text { Sciences, Inc. }\end{array}$ & $\begin{array}{l}\text { Lafayctte, } \\
\text { CA }\end{array}$ & $\begin{array}{l}\text { Relativistic } \\
\text { Magnetrons, } \\
\text { Theory }\end{array}$ & $\begin{array}{l}\text { Scaling laws; for explosive cathodes: } \\
\text { make plasmu more dense, reduce } \\
\text { plasma temperature, improve surface } \\
\text { conditioning }(30,31)\end{array}$ \\
\hline USA & $\begin{array}{l}\text { Air Force } \\
\text { Restarch } \\
\text { Laboratory }\end{array}$ & $\begin{array}{l}\text { Albuguerque, } \\
\text { NM }\end{array}$ & $\begin{array}{l}\text { Rekitivistic } \\
\text { Klystron, MILO, } \\
\text { Gyro BWO }\end{array}$ & $\begin{array}{l}\text { Careful tube design; brazed tube; } \\
\text { studies of space charge limited } \\
\text { effects in } B W O 5(3,25,27,32,33 \text {, } \\
39,57,12,13,60)\end{array}$ \\
\hline$\overline{U S A}$ & Comell University & Ithaca, NY & $\begin{array}{l}\text { TWT, ferroelectric } \\
\text { cathodes }\end{array}$ & $\begin{array}{l}\text { Investigate electron emission of } \\
\text { ferroelectric cathodes at high current } \\
\text { density ( } 46 \text { ) }\end{array}$ \\
\hline$\overline{\mathrm{USA}}$ & $\begin{array}{l}\text { Hughes Research } \\
\text { Labs }\end{array}$ & Malibu, CA & PASOTRONTM & $\begin{array}{l}\text { Avoid mole competition, desigin } \\
\text { high bandwidth components; control } \\
\text { plasma generation }(22,64)\end{array}$ \\
\hline$\overline{\mathrm{USA}}$ & $\begin{array}{l}\text { Texas Tecb } \\
\text { University }\end{array}$ & I.ubbock, TX & $\begin{array}{l}\text { Window and cavity } \\
\text { studies using } \\
\text { magnetron }\end{array}$ & $\begin{array}{l}\text { Clarify physical mechanisms leading } \\
\text { to electric breakdown }(16,36)\end{array}$ \\
\hline USA & \begin{tabular}{|l|l|} 
Titann \\
\end{tabular} & $\begin{array}{l}\text { Albuquerque, } \\
\text { NM }\end{array}$ & Super Reltron & $\begin{array}{l}\text { Keep rep. rate low with velvet } \\
\text { cathodes; use convertional tube } \\
\text { methods (29) }\end{array}$ \\
\hline$\overline{\text { USA }}$ & UC Davis & Davis, CA & BaO cathodes & $\begin{array}{l}\text { Improve curent density during } \\
\text { thermionic emission of cathodes }\end{array}$ \\
\hline USA & $\begin{array}{l}\text { University of } \\
\text { Maryland }\end{array}$ & $\begin{array}{l}\text { College Park, } \\
\text { MD }\end{array}$ & $\begin{array}{l}\text { Plasma-lilled } \\
\text { BWO, Phase- } \\
\text { locked Gyrotron }\end{array}$ & $\begin{array}{l}\text { Shireld plisma column in region of } \\
\text { diverging B-field to elimnate upper } \\
\text { hybrid resonance there }(67,68)\end{array}$ \\
\hline$\overline{U S A}$ & $\begin{array}{l}\text { University of } \\
\text { Michigar }\end{array}$ & $\begin{array}{l}\text { Ann Arbor, } \\
\text { MI }\end{array}$ & Gyrotron, Theory & $\begin{array}{l}\text { Investigate possible plasma effects } \\
\text { inside cavity thru diagnostic } \\
\text { experiments; understand } \\
\text { multipactoring for case of two } \\
\text { conducting surfaces and single } \\
\text { dielectric surface }(35,37)\end{array}$ \\
\hline$\overline{\mathrm{LSA}}$ & PRIMEX PI & $\begin{array}{l}\text { San Leandro, } \\
\mathrm{CA}\end{array}$ & $\begin{array}{l}\text { Relativistic } \\
\text { Magnetrons }\end{array}$ & $\begin{array}{l}\text { Move towards higher impedance } \\
\text { designs to lower temperature and } \\
\text { slow plasma; reduce all hydrogen } \\
\text { sources to levels consistent with } \\
\text { critical concentration analysis (30) }\end{array}$ \\
\hline$\overline{\text { USA }}$ & $\begin{array}{l}\text { University of New } \\
\text { Mexico }\end{array}$ & $\begin{array}{l}\text { Albuquerque, } \\
\text { NM }\end{array}$ & BWO & $\begin{array}{l}\text { Investignte behavior of plasma inside } \\
\text { tube with diagnostic experiments; } \\
\text { conduct plasma-filled BWO } \\
\text { experiments }(65,66,69,70)\end{array}$ \\
\hline
\end{tabular}

the subject [6]. Prospects for further advances are good, given the current emphasis and work being done on the problem.

The state of pulse shortening and the trend for the future can be depicted as shown in Fig. 1. This chart shows the past and current state of the HPM narrow band tube pulse shortening and the possible direction that it is headed in the future. In the past, pulse shortening gave rise to a figure-of-merit (product of RF peak power versus pulse length) of several tens of joules. Recent progress has improved this number. Current HPM technology, while still resulting in pulse shortening, produces a figure-of-merit of about $250 \mathrm{~J}$. One of the desired outcomes of HPM research is to achieve a radiated energy level per pulse measured in the kilojoule range without pulse shortening. In order to achieve this goal, the two phases of research will be required. This paper addresses the causes of pulse shortening and possible solutions to this problem that can be viewed as a multiphase approach.

\section{Pulse Shortening CAuses}

There are many causes that have been identified by many different groups, which contribute to the pulse shortening problem. Each of these research organizations has used different sources and/or configurations in their laboratories. It is useful, therefore, to lay out a framework for this discussion of the recent progress toward the elimination of pulse shortening. Several causes have been suggested by other authors. One suggested set involved two causes of pulse shortening, high field induced plasma formation and beam degradation due to interactions between the high power microwaves and the electron beam generating them [1]. Recent papers [7], [8] proposed a list of four general categories for the causes of pulse shortening. These categories are: 1) plasma generation; 2) electron streaming; 3) high electric fields; and 4) beam disruption. They will be used with some modifications as a start in describing the causes of pulse shortening. The categories include a number of cases in which the effect can be seen or produced that are discussed in succeeding sections.

These categories are not entirely independent. For example, plasma generation can be caused by any of the other three. Moreover, they do not readily explain all of the progress that has been made in increasing pulse length in HPM sources. Much of the improvement has been made with more fundamental work. The first stage is strategic. It comes before the stage at which working on one of the previous four causes can produce much progress. Thus, another category: 5) fundamental tube design issues can involve major or minor changes to the tube that may dramatically change the design or performance. This step is the one that must be done correctly to approach the limits that may be imposed eventually by the others. It was referred to by Koshelev et al. as the first step in getting to high energy. He discussed the production of a relativistic electron beam that generates microwaves efficiently, is not subject to instabilities, operates at modest $(<10 \mathrm{kG})$ magnetic field, and avoids high electric fields at surfaces in the tube [9]. The process of achieving this can be reached using clever design accompanied by particle-in-cell code calculations and iterative experiments to sort out gross design issues that are strategic rather than tactical. The rest of this review will use these five general categories for the purposes of comparing and contrasting the international effort in solving this difficult problem. 


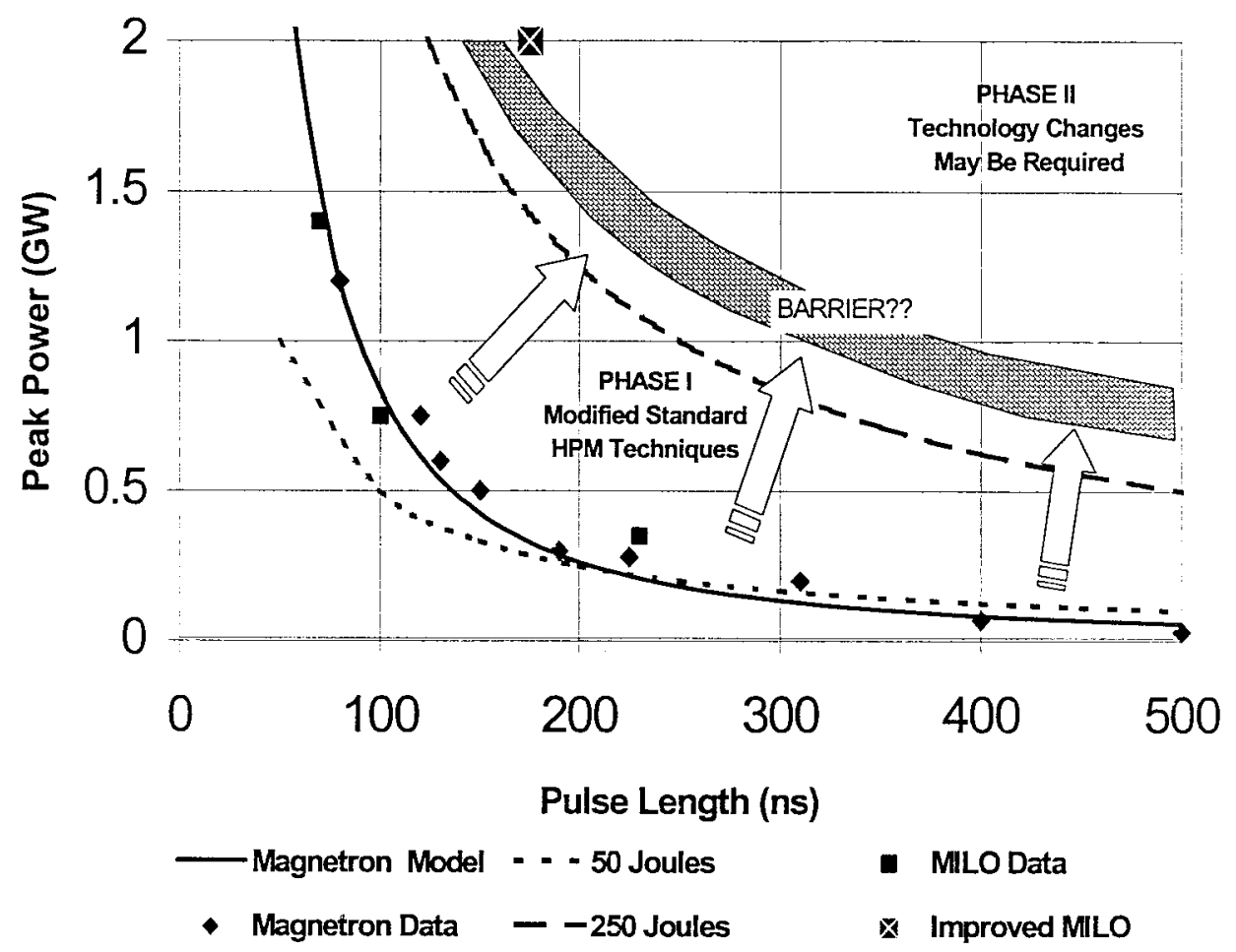

Fig. 1. Pulse shortening trends. Peak power versus pulse length has followed a nearly constant energy per pulse at a few tens of joules. Recent results suggest that a phased approach toward the elimination of pulse shortening has promise. Technological barriers may exist that prevent full implementation of Phase II goals for HPM sources. (MILO data taken from [60], magnetron model from [30], and magnetron data from [31]).

\section{Plasma Generation}

Unwanted plasma creation is one reason why the length of HPM pulses is shorter than the driving voltage source. In fact, there are many ways in which plasma generation can affect the performance of a microwave tube. A number of forms were defined in a recent paper on pulse shortening: gap closure, electron beam expansion, beam interception, and beam drift and diffusion [7].

Gap Closure: This involves the motion or expansion of plasmas in the diode region (cathode and/or anode). The effect can be a change in impedance or to the geometric boundaries of the microwave tube, causing different modes to be prevalent or stopping the designed mechanism from working. This effect seems to explain pulse shortening seen in relativistic magnetrons [8], [10].

Electron Beam Expansion: The plasma involved in generating the electron beam can diffuse leading to electron beam expansion [7].

Beam Interception: Collisions between electron beams and surfaces, (for example, on slow wave structures, choke structures, or elsewhere in the tube) generate a moving plasma, which can disrupt the coupling between the beam and microwave generating structures [7], [11]. It can also prevent establishing magnetic self-insulation in the MILO [12], [13].

Electron Beam Collection: Plasma can form at the collector when the electron beam dose on the surface exceeds 100 $\mathrm{J} / \mathrm{g}$, and may stream back along magnetic field lines into the microwave generation region [7]. This has been observed (and eliminated) at the General Physics Institute in microwave oscillators [11].
Plasma can be generated at a number of locations within HPM tubes, including the cathode, the collector, rf-induced emission from slow wave structures and cavities [3], [11], [14], [15] and at windows [16]. Excessive plasma generation in the interaction region of a plasma-filled backward wave oscillator (BWO) can also cause pulse shortening [17]. A very early Russian paper on pulse shortening [18] suggested that free electrons in the slow wave structure absorbed the microwave energy and caused the early cutoff of microwave energy in a relativistic BWO. Indeed, Russian researchers had by 1992 concluded that pulse shortening in conventional Cerenkov systems was due to the strong electric fields at the cavity walls and the associated plasma production [1]. Further work indicated that pulse shortening in the relativistic carcinotron was due to bombardment of the slow wave structure walls with relativistic electrons that generated a plasma. Moreover, work on the problem led to pulse lengthening to $400 \mathrm{~ns}$ [19]. A group at Nishny Novgorod has taken the approach of adopting hard tube techniques to solving pulse shortening. They have selected a thermionic cathode and materials for the slow wave structure that will minimize potential plasma generation at the slow wave structure and have adopted a regimen of surface cleaning to eliminate breakdown initiated by surface contaminants. The tube can be baked, and the $X$ band source has achieved $10-\mu$ s pulses and $5 \mathrm{MW}$ of power, an order of magnitude increase for both power and energy [20].

It is important to recognize that not all plasma in a microwave source leads to pulse shortening. In fact, some devices (BWO's) use the insertion of plasma to increase the efficiency of the microwave production [21]. Yet, these very same 
devices that use ion focusing to lead the electron beam into a desired path suffer from pulse shortening primarily due to unwanted plasma production in regions of the tube other than those intended for containment of the electron beam. Moreover, in other devices such as traveling-wave tubes (TWT's), a gas-electron beam induced plasma can lead to ion focusing that has the effect of moving the electron beam away from the desired location for microwave production [22].

There is a unique feature about HPM tubes that must be considered when discussing the pulse shortening problem. Unlike the tubes mentioned above, the extremely high power associated with HPM tubes of the gigawatt class has to date resulted from explosive emission cathodes for which the production of plasma is an inherent feature. This type of cathode makes possible the high current that drives the tubes from a few to $100 \mathrm{kA}$ in a relatively small diode. Velvet is often used to get superior cathode performance in the range of tens to hundreds of amperes per square centimeter at relatively low field stress (tens of kilovolts per centimeter). For example, velvet enables the MILO [3], [23] to generate over $1 \mathrm{GW}$ in a compact package with a cathode that generates in excess of $60 \mathrm{~A} / \mathrm{cm}^{2}$. There are indications that elimination of plasma generated by complete cleaning of explosive emission cathodes causes the emission of electrons to be severely diminished or eliminated [24]. Mesyats pointed out that the explosive emission cathodes also contribute to the relative simplicity of HPM sources compared to conventional tubes with thermionic cathodes, which is an important feature [1].

However, the gigawatt class sources have exhibited pulse shortening. The explosive emission cathodes are designed to be compatible with the very high pulsed power machines that drive them. These machines typically use plastic dielectrics and O-rings in the vacuum interfaces that preclude the extremely high vacuum characteristic of hard tube technology. Moreover, the use of explosive emission cathodes creates plasma in the A-K gap during the electron generation process. The plastic insulators and plasma in these HPM tubes limits the vacuum achieved to the range of $10^{-5}-10^{-6}$ torr at best. However, it is precisely the plasma process which also produces the very high current that drives the tube operation to the multi-gigawatt level [25]-[28].

Plasma generated due to velvet cathodes and electron emission from the cathode have also been seen to have a multiple pulse effect, coating additional surfaces with gas that then affects later pulses [29].

In magnetrons, the effect of plasma growth from the cathode can be to effectively increase the size of the cathode. This can change the magnetron resonance condition, moving the magnetron out of an operable regime that can couple out microwave energy as the cathode plasma increases [30]. The effects of increasing cathode size has been modeled, and the magnetron has been shown to vary in frequency, starting time of the radiation, spectral purity of the waveform, and shortening of the pulse as the radius is increased [10]. A good example of the complexity of pulse shortening and its dependency on the type of tube can be found by examining the issue of diode impedance collapse. This plasma process is believed to cause pulse shortening in magnetron tubes and others. A paper [31] in this issue presents scaling laws and data from several locations supporting the accuracy of these relationships. The basic pulse shortening relationship given for explosive emission when using Child-Langmuir law is

$$
E \propto \frac{1}{\sqrt[3]{\tau^{2}}}
$$

Here, $\tau$ is the pulse length and $E$ is the microwave pulse energy. This implies that there is an inherent limitation to the energy that can be radiated for a given pulse. That is, if you want to have longer pulses you must live with less energy per pulse [31].

There are some microwave tubes, however, that do not follow this scaling law. For example, recent results with the Reltron tube [29] have clearly shown that velvet explosive cathodes do not cause pulse shortening and are not the limiting factor in the power output of this device. This is apparently due to the fact that the Reltron tube has a large gap and radial motion of the plasma is not as dominant as in other tubes. Hence, the above scaling law can be applied to explosive emission cathodes when radial motion of the plasma is dominant.

Progress in pulse shortening in the MILO has been achieved during the past two years without assuming that the mechanism cited in this paper governs the power and pulse length. Both power and pulse length as well as energy have been increased [32], [33], contrary to the model prediction that not only must pulse length suffer with increased power, but also, especially, energy must be reduced with increasing pulse length [31]. The authors' explanation of the limited agreement being due to mechanisms other than that of the model appears to be correct. Another group has also modeled the relativistic magnetron, and they have evidence that pulse shortening in these devices can be eliminated by increasing the voltage during the pulse [34].

On the other hand, recent Reltron tube experiments [29] have shown that pulse length can be affected by the pulse repetition rate. Miller theorizes that this form of pulse shortening is caused by the generation of ions (plasma) in the A-K gap which backbombard the cathode releasing additional gas. The result can be severe. Equation (2) provides an empirical upper bound for the pulse length:

$$
\tau[\mathrm{ns}]<\frac{20 S[1 / \mathrm{s}]}{R[\mathrm{~Hz}]} .
$$

Here, $S$ is the pumping rate, $R$ is the repetition rate, and $\tau$ is the pulse length. Thus, for a tube using a velvet cathode and explosive emission, in order to run a $1 \mu \mathrm{s}$-long pulse at a 1 $\mathrm{kHz}$ rep-rate a pumping speed of at least $50000 \mathrm{l} / \mathrm{s}$ is required. Thus, a more realistic goal for such cathodes may be in the vicinity of tens of hertz repetition rate for a $1-\mu$ s pulse length.

Microwave fields can be sufficiently intense to cause plasma-induced breakdown at windows. Researchers at Texas Tech University have observed glow discharges associated with breakdown at field strengths (tens of kilovolts per centimeter) well below that required for multipactoring (100 $\mathrm{kV} / \mathrm{cm}$ ) [16]. Likewise, breakdown at the antenna interface and walls limited (for a time) the performance of the relativistic klystron oscillator [33]. 


\section{EleCtron StREAMing}

Electron streaming occurs where cathode plasma electrons move away from the accelerating gap causing diode impedance degradation. Another possible streaming mechanism, especially in linear microwave devices, occurs when electrons collected at the beam dump are able to overcome the beam potential and stream back toward the slow wave structure. Any electrons produced in the slow wave structures can cause pulse shortening [7]. Thus, electron streaming, from the diode region or the collector of a linear device, has the potential to shorten the pulse length considerably.

The General Institute of Physics (GPI) in Russia has reported a good example [11], [19] of this behavior and its effect on pulse length. In an extensive study of pulse shortening using their carncinotron (relativistic BWO) this group demonstrated that once the streaming of electrons from the collector region of their BWO had been eliminated, the pulse length grew by a factor of two-from 200-400 ns. However, they also reported that the pulse length of the RF was still terminated early by other effects compared to the beam duration, about $800 \mathrm{~ns}$.

\section{High ELECTRIC FIELDS}

In all types of HPM tubes, keeping the electric field stresses to a minimum, especially close to cavity walls, and other surfaces, is critically important. Electrical breakdown, socalled "arcs and sparks" will cause the tube to turn off its RF emission [22], [26], [27]. This can be due to the creation of breakdown-induced plasma and the disruption of the critical balance of the beam and cavity that must be present to produce microwaves efficiently in such tubes. Additionally, breakdown at windows can absorb microwave energy and cause reflection of the microwaves, terminating the radiated power from a source. A group at Texas Tech University is pursuing a systematic study of breakdown at windows and cavities [16]. High electric field stresses at slow wave structure walls in carcinotrons and BWO's can generate emission and plasma that can interfere with microwave generation [1], [15]. Research is also being done on microwave induced breakdown at surfaces at the Institute of Electrophysics in Russia with a view to finding surface treatments that may raise the threshold for breakdown [15].

Coupled with the problem of high electric fields is the issue of baking and "out-gassing" the tube. By reducing the hydrocarbon constituents and other contaminants in the tube, itself, the electrical breakdown threshold will be increased. The ideal tube, therefore, uses ceramic construction and other materials that do not readily adsorb molecular contaminants.

The Reltron tube has been experimentally studied for the effects of electrical breakdown [29]. The TITAN Corporation research team discovered that the pulse shortening problem for this post-acceleration device was the result of a mechanism involving RF electric-field-induced gas evolution and subsequent ionization. By replacing grid structures in the Reltron output cavities, they were able to decrease the peak field stresses to below $150 \mathrm{kV} / \mathrm{cm}$ and dramatically improve the energy per pulse by a factor of two.
The process known as multipactoring, or secondary electron resonant discharge (SERD), is closely associated with high electric fields. During multipactor discharge [35]-[37], a metallic or dielectric surface is exposed to RF electric fields. Under certain conditions, the number of secondary electrons emitted from the surface can grow under action of the RF microwave fields and a DC field (in the case of single surface dielectric multipactoring). Under severe conditions multipactoring can result in destruction of ceramic RF windows, erosion of metallic structures, melting of internal components, and perforation of vacuum walls. Not only can these effects be catastrophic to tube operation, they can also cause pulse shortening as surface erosion material interferes with the beam-field interaction. Research at the Institute of Applied Physics has shown that SERD-induced pulse shortening due to emission on slow wave structures in a relativistic carcinotron can be eliminated. This is possible by adoption of hard tube cleanliness to eliminate adsorbed gas. The proper selection of materials that will not generate gas under high electric fields must, of course, also be pursued since SERD can be produced from the surface, itself, as well as from contaminants [20], [38].

\section{BEAM DISRUPTION}

In beam disruption, the electron beam is interrupted or diverted from the designed optimum path for microwave generation. Beam disruption includes such phenomena as plasma instabilities, beam drift and diffusion. A variety of situations can lead to loss of stability in the electron beam that drives the microwave production process. The field strength in the vicinity of the electron beam can be large enough to disrupt the beam. This has been observed in multiwave Cerenkov generators and relativistic diffraction generators. When this happens the beam strikes the slow wave structure or other parts of the tube and substantial plasma generation (and in some cases damage) results, in addition to disrupting the relationship of the beam to the slow wave structure [7], [9]. In some circumstances, high microwave fields can cause beam breakup, for example, causing the electron beam to go from a cylinder optimized for strong interaction with a slow wave structure into jets of electrons [1].

Beam disruption can also occur in plasma-filled BWO's and TWT's due to instabilities induced by beam-plasma interactions [22]. The distance from the beam to the slow wave structure can be changed by ion focusing. This causes the beam to pinch, moving the current away from the optimum position relative to the slow wave structure for microwave generation in gassy TWT's and in BWO's. This can be a selfgenerated effect stemming from increased gas pressure and plasma formation due to outgassing from surfaces [22].

Space charge formation is another pulse shortening mechanism. When the relativistic electron beam is operating near the space charge limit, a space charge can develop that impedes the beam from following a path that can produce microwaves. This pulse shortening mechanism has been proposed [39] for gyro devices that are capable of operation near the space charge limit (SCL) like the gyro-BWO. This proposed effect, seen 
in computer simulations, comes about from instability in the electron beam that prematurely induces the SCL to be reached. If validated through experiment, this limit may not be possible to overcome as it involves the fundamental mechanism of microwave generation for such devices. Pulse shortening has also been seen in relativistic klystron amplifiers (RKA's) due to space charge effects. Klystrons can produce strong electric fields at cavities, strong enough to prevent some of the less energetic electrons to pass the gap. This leads to reflection of the electrons and can lead to formation of a space charge that has been reported in RKA's [14], [40]. Similar effects have been observed in simulations of the relativistic klystron oscillator when the gap field is allowed to get too large [41].

\section{TUBE DESIGN}

Tube design is included as a cause of pulse shortening because it is needed to explain much of the progress to date in improving pulse length performance. Optimal tube design must be the first goal of a the high power microwave tube researcher when addressing the problem of pulse shortening. Without it, the other possible causes which were discussed above may not even be possible to observe. Koshelev [9] regards it as the first step in getting to high energy, and it has been the experience in Air Force Research Laboratory work as well. Tube design also includes steps that lead to high power performance. These steps include production of a relativistic electron beam that generates microwaves efficiently, is not subject to instabilities, operates at modest $(<10 \mathrm{kG})$ magnetic field, and avoids high electric fields at surfaces in the tube [9]. Proper tube design includes steps that are needed to avoid some of the other four causes discussed above, but it also suggests design subtleties that are not obviously related to them. The introduction of a choke into the design of the MILO doubled performance of the tube by reflecting the backward wave in phase with the forward going wave [3], [26]. The inclusion of a taper in the cathode structure avoided high field stress at the choke. Elimination of emission in the region where it could intercept the last choke vane was an important step in reducing pulse shortening. This change enhanced formation of the magnetic self-insulating beam needed to drive the microwave-producing interaction [12], [13]. In like fashion, changing the design to eliminate high field stresses in the tube's extraction region avoided electron bombardment of the cavity vanes. The tube design was changed to avoid the effects of UV radiation in the MILO. These steps in tube design corresponded to Koshalev's first step on the path to high energy.

A strategic design approach to avoiding pulse shortening for relativistic Cerenkov devices has been suggested by several Russian groups. One group at the Institute of High Current Electronics, Tomsk, Russia, is working to improve the performance of their 3-GW relativistic BWO. The field strength on the slow wave structure has been determined to be high enough to initiate electron emission from its surface. This has resulted in $6 \mathrm{~ns}$ pulses of RF for a 45-ns pulsed power machine, the Sinus 7. The proposed solution is to design a large overmoded source to drop the field strength at the walls to a safe level [42]. Researchers at the Institute of Applied Physics at Nishny Novgorod suggest a similar approach [43]. The latter group also used the approach of eliminating the explosive emission cathode in favor of a thermionic cathode and also used selection of materials and a program of degassing the slow wave structure. This approach worked, raising the output power by a factor of ten, to $5 \mathrm{MW}$, and the pulse length to $10 \mu \mathrm{s}$.

Mode competition generated by pulsed power variation, reflection, and buildup of unwanted modes in the slow wave structure caused pulse shortening that required design changes in a plasma-filled PASOTRON BWO [17].

Progress in eliminating pulse shortening in the relativistic klystron oscillator has resulted in part from the recognition of the crucial role of pulsed power and cathode performance in the operation of the tube. The ramping of the voltage was seen to produce a turn-on of the microwave production process only in a narrow range for the tube. Designing out this cause of pulse shortening requires careful attention to design of a number of system components [32], [33].

\section{REMEDIES FOR PULSE SHORTENING}

The progress in understanding the causes of pulse shortening in HPM tubes has led to some advances in the art and some as yet unexplored ideas that may offer further improvements. Many of these were discussed in a recent workshop that provided considerable insight into the problem and potential solutions [6]. The remedies are not all achievable in any or all types of tubes, but some are of general use.

Since unwanted plasma comes from a variety of sources, there have been many successful approaches used to address this problem. Many of these approaches amount to making the components of the source as clean as possible where the beam and microwaves exist. Another important factor is to provide as good a vacuum in the tube as can be provided. This is, of course, the standard microwave tube approach.

One set of recommendations is to focus on cleaning the anodes of magnetrons to avoid plasma generation from electron bombardment using vacuum processing involving hydrogen and vacuum furnaces, storage of cleaned parts in vacuum or nitrogen, and (as required) heating of the assembled tube under vacuum. Ultimately, this leads to hard vacuum-sealed tube technology with attendant cost and window difficulties [10].

A second set of suggestions follows [30]: use a thermionic cathode to avoid plasma generated from the cathode that then grows and destroys the microwave generation process. If this is not possible, then use the scaling law indicated in (1) as a guide. For magnetrons, the power versus pulse length can be stated [30] as:

$$
P f \tau^{5 / 3} \propto \frac{\eta}{Q}\left(\frac{m_{p}}{\rho_{\text {cath }}}\right)^{5 / 6}
$$

where $P=$ peak power of the radiated pulse, $f=$ frequency, $\tau=$ pulse length $\eta=$ electric conversion efficiency, $m_{p}=$ mass of the lightest plasma ion species, $Q$ is the ratio of the cavity stored energy to output power, and $\rho_{\text {cath }}=$ cathode resistivity. That is, $\tau$ can be made larger by improving electric conversion efficiency $(\eta)$ and output coupling (lower $Q$ ), in- 
creasing mass of the cathode plasma ions $\left(m_{p}\right)$ slowing growth of the cathode plasma, and increasing conductivity of the cathode material (decrease $\rho_{\text {cath }}$ ). Note that the longer pulses are favored by lower frequency sources. Also, new cathode technology such as the recent work [44] done with cesium iodide (CsI) and the work [45], [46] done with ferroelectric materials shows promise. The CsI studies indicate that it may reduce pulse shortening [30]. CsI loaded carbon fiber diodes provide uniform electron emission at lower electric field stress enabling operation at higher vacuum diode impedance. The higher impedance reduces the current and slows the plasma transport. Lower field strengths will mitigate breakdown within the cavity. Ferroelectric cathodes have been studied extensively and do produce high current densities at lower voltages, but further basic research is required to make the technology feasible for HPM applications [45].

For the high power Reltron tube, longer pulses can be achieved using explosive cathodes if the repetition rate is kept to a few tens of hertz. Clearly, research into new cathode materials which explosively emit at low turn-on fields but liberate much less material from its surface would help to make further gains in long-pulse, high-current, high power tubes.

Several sets of remedies have been proposed for the class of Cerenkov devices, backward wave oscillators (BWO), relativistic carcinotrons, multi-wave Cerenkov generators (MWCG), TWT's, and relativistic diffraction generators (RDG). Koshelev's steps [9] constitute the first phase of treatment for pulse shortening. This is accomplished by theoretical and experimental work, and is followed then by a second phase of "technological" steps that focus on beam forming and transport, attention to materials, vacuum conditions, and conditioning. The last two steps are hard to accomplish with an explosive emission cathode, so the earlier procedures are most important for that case. Their recommendations are based upon a number of MWCG and RDG experimental investigations, including multi-gigawatt work by Bugaev et al. at the Institute of High Current Electronics [9], [47].

Ilyakov et al. [38] recommend the use of Cerenkov devices with a cross section as large as the wavelength of the radiation as a good prospect for multi-megawatt, multi-microsecond pulses. The very nature of these devices put a lower electric field stress on the slow wave structures walls. They achieved a pulse length increase of $5-\mathrm{MW}$ pulses from $500 \mathrm{~ns}$ to $8 \mu$ s through a program of baking, pumping, and 40-50 conditioning pulses, with a vacuum that was $10^{-8}$ torr in the slow wave structures and higher in the cathode region [38]. This is an encouraging result because it indicates that it may be possible to achieve greater pulse lengths without extensive conditioning as is done in hard tube technology. A similar approach involving a large dimension slow wave structure for low field stress was adopted for a high power BWO operating at C-band [42]. Large transverse geometry TWT's with multi-channel feedback loops have been also used [48] to keep electromagnetic field stresses low, while still producing isolated modes.

A set of prescribed steps are proposed for these devices that seek to avoid pulse shortening problems with vacuum carcinotrons by keeping the field at the electron beam low to avoid beam breakup and by keeping the beam well away from the waveguide wall. These steps are: 1) create a stable beam for $1 \mu \mathrm{s}$; 2) capture the electron beam in a collector/trap; and 3) use charge neutralizing plasma to guide the electron beam and to avoid space charge disruption of the beam [49].

Another novel approach to extending the pulse length in megawatt generators has been proposed by a group at the Moscow Radiotechnical Institute [50]. In this scheme, they propose to use a two-beam cathode to produce an extremely fast rise time in the current pulse. In this way, the microwave tube will not be filled with electrons and fields before the generator is fully operational.

The conventional tube manufacturers have a common view of the way to proceed to make microwave tubes work at long pulse lengths. The process is one that has the benefit of much experience and results in tubes that are commercially viable [51]. The pinnacle of the art at present is the SLAC DESY Sband klystron tube that produces $150 \mathrm{MW}$ with a pulse length of $3 \mu \mathrm{s}$. It is operable at $60 \mathrm{~Hz}$, with an energy per pulse of 450 J. It has been run as high as $190 \mathrm{MW}$, for an energy in excess of $500 \mathrm{~J}$ [52], [53]. These tubes, however, are too large for some applications. Moreover, the requirement for a substantial electromagnet or superconducting magnet system makes the tube system heavy, and perhaps, difficult to supply with power under certain operating conditions. It has been proposed that multi-kilojoule tubes could be produced as an offshoot of the technology by adopting the approach of multiple beam klystrons using periodic permanent magnet (PPM) focusing to guide the electron beams rather than the heavier and power hungry electromagnets [54]. This is an attractive idea, and hopefully the funding required to do it can be found.

On the other hand, the HPM community has worked in a number of laboratories on relativistic klystrons. Los Alamos has produced a relativistic klystron with peak power of 475 MW, half-power pulsewidth of $0.5 \mu$ s and 160-J pulse energy [14]. The Naval Research Laboratory has done extensive work on a RKA that has achieved multi-gigawatt power at $\mathrm{L}$ and $\mathrm{S}$ band [55], [56]. Work at the Air Force Research Laboratory (formerly the Phillips Laboratory) on the RKA and more recently on an injection locked relativistic klystron oscillator (RKO) has achieved a power in excess of $1 \mathrm{GW}$ [27], [32], [33], [57], [58]. Progress has been made in resolving pulse shortening so that the tube operates for the duration of the pulsed power, producing $170 \mathrm{~J}$ and $1.5 \mathrm{GW}$. This improvement was accomplished as a result of developing an understanding of the mechanism limiting the pulse. The Air Force Research Laboratory RKO was affected by the ramping current pulse from the cathode, which moved the current out of the operating regime for microwave production during the pulse. Improving the cathode performance led to more stable current and enhanced pulsewidth. Previous work had eliminated breakdown at points in the tube. The improvement was made without adopting the rigors of hard tube technology [12]. The work is now pulsed power limited, and further progress awaits a longer pulse modulator.

In some instances, a partial "hard tube" approach may be warranted and successful. For example, at the Air Force 
Research Laboratory, the MILO has achieved $2 \mathrm{GW}$ and in a longer pulse so that a pulse energy of $300 \mathrm{~J}$ has been achieved. This work includes the partial adoption of the hard tube technology that has been recommended so forcefully [51], [59]. The MILO has been the focus of much work over the past three years with improvement in the understanding of how the tube works and significant progress as a result of it [3], [12], [13], [26], [60]. Most recently, a new tube has been constructed with the substantial assistance of the Stanford Linear Accelerator Center (SLAC) that is brazed and follows the hard tube construction techniques so that higher vacuum can be explored in future work. The performance of the MILO has been improved by changes to the cathode region with a result that the tube operates now for the duration of the pulsed power available, and it is not now exhibiting pulse shortening. Further progress is awaiting a longer pulse machine for the research [60]. Although the MILO does not now exhibit pulse shortening, and we have yet to explore the high vacuum regime favored by the tube manufacturers, the planned improvements to our pulsed power may again require us to address the issue at a longer pulse length. Some of this work would address the pulsed power incompatibility with high vacuum and heat treatment. The Air Force Research Laboratory team plans to explore the hard tube technology following the addition of new equipment. This research is possible as a result of collaborations with AFOSR and the MURI consortium universities [4], [61].

Recently reported work in the U.K. has disclosed the achievement of $1.75 \mathrm{GW}$ and a pulsewidth of $200 \mathrm{~ns}$, pulse energy of $250 \mathrm{~J}, 30 \%$ tunable bandwidth, and an efficiency of $25 \%$. The tube is a tapered MILO that operates at $50 \mathrm{ohms,}$ which is an order of magnitude higher than the impedance of the Air Force Research Laboratory MILO. The device operates like other HPM tubes at modest vacuum and without baking and without extensive conditioning [62].

\section{CONCLUSIONS AND RECOMMENDATIONS}

The problem of pulse shortening is being addressed in a number of laboratories for diverse HPM sources. Overall, progress in pulse shortening is being made and the future for HPM tubes to achieve higher power than ever is promising. The improvements to HPM tube performance can be considered in terms of two phases of effort. Phase I comprises attention to the design of the microwave production mechanism with an emphasis on cathode performance, beam transport, beam dump, cavity or slow wave structure, and elimination of arcing and breakdown at points within the tube. Phase I can be accomplished at modest vacuum $\left(10^{-4}-10^{-6}\right.$ torr). To date, Phase I efforts have led to improvements in a number of tubes [12], [27], [57]. Phase II involves careful attention to materials selection, materials conditioning, baking, tube conditioning, and high vacuum technology $\left(10^{-8}-10^{-9}\right.$ torr). The Phase II steps are essentially the difference in practice between present HPM technology and conventional microwave tube manufacturing technology.

Energetic pulsed power-based HPM technology has been used to achieve this progress to-date. As mentioned above, this technology mostly uses explosive emission cathodes, plastic O-rings and other parts, aluminum, etc. so that the vacuum achievable is in the $10^{-5}-10^{-6}$ torr range. In the last year or two, a "hybrid" technique has been tried in a few instances, and is the subject of current research. The "hybrid" technique employs some of the features of the conventional tube industry. Progress has been achieved mostly due to a maturing technology of improved design, construction, and understanding of the beam interaction region.

Conventional tube technology (e.g., as used in nonrelativistic magnetrons and klystrons) uses sealed, carefully crafted manufacturing techniques which employ thermionic cathodes, ceramic materials, and high (hard) vacuum below $10^{-9}$ torr. In addition, these tubes are extensively baked and conditioned before use. The conventional tube manufacturers claim that pulse shortening does not exist in their tubes. However, the steps taken by these manufacturers constitute expensive and demanding procedures to ensure that pulse shortening does not happen. This leads to tube performance at the levels attained, but the process is not a trivial one.

The question, and future direction, for the HPM tube developer is whether or not a barrier exists in achieving higher radiated energies beyond the several hundred joules seen to date. Will it be necessary to use conventional technology (hard tubes) to achieve greater than the $1 \mathrm{~kJ}$ target energy? Or, will we be able to push standard HPM, or hybrid, approaches to get to the multi-kilojoule levels? The answers to these questions await future research now being conducted a number of institutions around the world.

However, a number of conclusions have emerged that provide guidance to this future work on high energy HPM tubes, as a result of the progress made to date. These recommendations are as follows.

1) HPM tubes can be improved by the use of theoretical modeling using PIC codes to provide guidance to improvements to the design of the sources. When combined with an experimental program, rapid progress can be made that can increase power and pulsewidth. This progress is not dependent upon attainment of high vacuum and baking. This is perhaps a first step toward an optimum HPM source.

2) In designing HPM tubes for long pulses, field strengths in cavities and at slow wave structures should be kept below $150 \mathrm{kV} / \mathrm{cm}$. In some cases, structures large compared to the wavelength (which maintain mode stability) offer a means of lowering the stress at the boundaries of the tube [63]. Grids should be replaced where possible with structures that do not intersect the path of the electron beam. These steps will help avoid unintended plasma generation.

3) Care should be taken to avoid multipactor or secondary electron resonant discharge (SERD) and the concomitant uncontrolled plasma generation.

4) Explosive emission or cold cathode current generation creates plasmas that must be controlled. An alternative approach is to explore different cathode technologies that are compatible with hard tube requirements. These should be able to be baked at $500{ }^{\circ} \mathrm{C}$ cleanable, ca- 
pable of pumping to high vacuum, and have emission characteristics that are in the range tens to hundreds of amperes per square centimeter to be comparable to the performance of explosive emission cathodes. However, Mesyats points out that this may introduce additional complications into HPM tubes, whose simplicity in part stems from the explosive emission cathode [1]. Alternate forms of explosive emission cathodes should also be explored, although it is not clear that extremely clean ones will perform as well as those used at the present time. Cathode materials should be chosen to avoid light plasma ion formation in order to delay diode closure. The use of heavy materials where plasma may be formed can delay diode closure. Cathodes are an area for innovation that can have substantial impact in reducing pulse shortening.

5) Windows and other dielectric breakdown must be addressed by suitable design and use of coatings. Considerations include the avoidance of electron and bremsstrahlung induced plasma formation inside the window as well as air breakdown on the other side.

6) Beam propagation must be maintained through design to avoid turbulence and beam instabilities. This requires theoretical and experimental attention to ensure that the beam will continue to go where it can make microwaves for a long enough time to meet the desired pulse length. The accomplishment of this goal is not easy, as the potential causes of beam disruption are several. Improvements to nonintrusive diagnostics that can be used near electron beams, slow wave structures, and cavities are needed to clarify the diagnosis of the problem for a number of sources. The use of plasmas to assist in guiding the electron beam has been shown to have merit, and improved methods for the controlled use of plasmas in sources should be explored [64]-[70].

7) Attention must be given to materials selection and surface treatments to avoid the creation of plasmas from absorbed air and water molecules, etc. This imposes standards of cleanliness that in the extreme are common in hard tube technology. Steps in this direction include cleaning parts, RF cleaning, baking, and higher vacuum than is customary among most HPM tubes. This includes a departure from the present HPM systems that use plastic insulators and O-rings at the interfaces to the microwave tube. The inclusion of ceramic seals and windows will be needed to permit the cleaning, baking, and high vacuum needed. The path to high energy may require the adoption of hard tube technology, but that is yet to be demonstrated at the GW power level. This path should be explored.

8) The prospect of driving multi-GW tubes with multimicrosecond pulse lengths at $60 \mathrm{~Hz}$ for days to condition HPM tubes would require modulators, cooling, etc. that dwarf the presently expensive conditioning costs. An important feature will be the development of alternatives to present methods used in the tube industry, and RF cleaning, use of short pulses during conditioning, and combinations leading to less conditioning should be explored. The Air Force Research Laboratory intends to follow closely the work of Gilgenbach et al. [24] at the University of Michigan in RF cleaning of microwave sources.

\section{ACKNOWLEDGMENT}

The author wishes to thank Dr. J. Gaudet for assistance in assembling information presented here and also thanks Profs. E. Schamiloglu, Y. Y. Lau, R. Gilgenbach, and Dr. J. Benford for helpful discussions on pulse shortening. He also thanks Prof. D. Parkes for assistance with the recent "International Workshop on High Power Microwave Generation and Pulse Shortening" that brought much focus to the global scope of the problem and its potential solutions.

\section{REFERENCES}

[1] G. A. Mesyats, "The problem of pulse shortening in relativistic microwave generators," High Power Microwave Generation and Applications, ISPP-10 Piero Caldirola E. Sindoni and C. Wharton, Eds. SIF, Bologna, Italy, 1992.

[2] S. N. Voronkov, O. T. Loza, and P. S. Strelkov, "Limits on the length of radiation pulses generated by microwave oscillators using microsecond relativistic beams," Sov. J. Plasma Phys., vol. 17, no. 6, pp. 439-442, June 1991

[3] S. E. Calico, F. J. Agee, M. C. Clark, R. W. Lemke, and M. C. Scott, "Rep-rate operation of a magnetically insulated line oscillator (MILO)," in Proc. First Int. Workshop on Crossed Field Devices, Univ. Michigan, Aug. 15-16, 1995, pp. 147-158.

[4] R. J. Barker and F. J. Agee, "National university consortium on microwave research (NUCOMR)," in Proc. SPIE 2557, 1995, pp. 300-309.

[5] F. J. Agee, "Basic research in high power microwaves," in Dig. Tech. Papers, Int. Workshop on High Power Microwave Generation and Pulse Shortening, Edinburgh, U.K., June 10-12, 1997, pp. 1-8.

[6] F. J. Agee and D. M. Parkes, Chairmen, see Dig. Tech. Papers, Int. Workshop on High Power Microwave Generation and Pulse Shortening, Edinburgh, U.K., June 10-12, 1997.

[7] J. Benford and G. Benford, "Survey of pulse shortening in high-power microwave sources," IEEE Trans. Plasma Sci., vol. 25, pp. 311-317, Apr. 1997.

[8] J. Benford and G. Benford, "Pulse shortening in high power microwave sources," in Dig. Tech. Papers, Int. Workshop on High Power Microwave Generation and Pulse Shortening, Edinburgh, U.K., June 10-12, 1997, pp. $75-80$.

[9] V. I. Koshalev, "Limitation of microwave pulse duration in high-power multiwave generators," in Dig. Tech. Papers, Int. Workshop on High Power Microwave Generation and Pulse Shortening, Edinburgh, U.K., June 10-12, 1997, pp. 91-96.

[10] X. Chen, M. Esterson, and P A. Lindsay, "Computer simulation of a high-power magnetron and the possible implications for rf pulse shortening," in Dig. Tech. Papers, Int. Workshop on High Power Microwave Generation and Pulse Shortening, Edinburgh, U.K., June 10-12, 1997, pp. $37-43$.

[11] O. T. Loza and P. S. Strelkov, "Microwave pulse shortening in relativistic high-current microwave oscillators," in Dig. Tech. Papers, Int. Workshop on High Power Microwave Generation and Pulse Shortening, Edinburgh, U.K., June 10-12, 1997, pp. 103-108

[12] K. Hendricks, M. Haworth, D. Schiffler, G. Baca, T. Spencer, M. Arman, L. Bowers, K. Hackett, S. Calico, T. Englert, M. Sena, D. Ralph, M. Scott, D. Trujillo, R. Lemke, M. C. Clark, P. D. Coleman, and R. Gallegoes, "Results of research on overcoming pulse shortening of GW class HPM sources," in Dig. Tech. Papers, Int. Workshop on High Power Microwave Generation and Pulse Shortening, Edinburgh, U.K., June 10-12, 1997, pp. 81-90.

[13] M. D. Haworth, K. E. Allen, G. Baca, J. N. Benford, T. J. Englert, K. E Hackett, K. J. Hendricks, D. M. Henley, R. W. Lemke, D. Price, D. R. Ralph, M. D. Sena, D. A. Shiffler, T. A. Spencer, "Recent progress in the hard-tube MILO experiment," in Proc. SPIE 3158, Intense Microwave Pulses V, 1997, pp. 28-39. 
[14] M. V. Fazio, W. B. Haynes, B. E. Carlsten, and R. M. Stringfield, "A $500 \mathrm{MW}, 1 \mu \mathrm{s}$ pulse length, high current relativistic klystron," IEEE Trans. Plasma Sci., vol. 22, pp. 740-749, Aug. 1994.

[15] S. A. Barengolts, M. Yu. Kreindel, and E. A. Litvinov, "Initiation of explosive emission in microwave fields," in Dig. Tech. Papers, Int. Workshop on High Power Microwave Generation and Pulse Shortening, Edinburgh, U.K., June 10-12, 1997, pp. 69-73.

[16] A. Neuber, J. Dickens, D. Hemmert, K. Krompholz, L. L. Hatfield, and M. Kristiansen, "Window breakdown caused by high-power microwaves,", this issue, pp. 296-303.

[17] D. M. Goebel, "Performance and pulse shortening effects in a 200-kV PASOTRON HPM source," this issue, pp. 354-365.

[18] A. S. El'chaninov, F. Ya. Zagulov, S. D. Korovin, G. A. Mesyats, and V. V. Rostov, "Limitation on the length of high-power microwave pulses in a relativistic carcinotron," Sov. Tech. Phys. Lett., vol. 7, no. 10, pp. 499-500, Oct. 1981.

[19] O. T. Loza, P. S. Strelkov, and S. N. Voronkov, "Plasma in a high-power relativistic generator retarding structure," Plasma Phys. Rep., vol. 20, no. 4, pp. 374-379, 1994.

[20] E. V. Ilyakov, G. S. Korabylov, I. S. Kulagin, and N. I. Zaitsev, "Relativistic carcinotron with a thermionic injector of electrons," this issue, pp. 332-335.

[21] Y. Carmel, K. Minami, W. Lou, R. A. Kehs, W. W. Destler, V. L. Granastein, D. K. Abe, and W. L. Lou, "Demonstration of efficiency enhancement in a high-power backward-wave oscillator by plasma injection," Phys. Rev. Lett., vol. 62, pp. 2389-2392, 1989.

[22] D. M. Goebel, "Pulse shortening causes in high power BWO and TWT microwave sources," this issue, pp. 263-274.

[23] M. Litz and J. Golden, "Repetitive explosive whisker emission cathode investigation," Proc. SPIE 2154, 1994, p. 110.

[24] R. Gilgenbach, private communication, 1997.

[25] S. P. Bugaev, V. I. Kanavets, A. I. Klimov, V. I. Koshalev, A. I. Slepkov, and V. A. Cherepinin, "Interaction of an electron beam and an electromagnetic field in a multiwave $1010 \mathrm{~W}$ Cerenkov generator," Sov. J. Comm. Tech. Electr., vol. 32, pp. 79-87, 1987.

[26] F. J. Agee, S. E. Calico, K. J. Hendricks, M. Haworth, T. Spencer, D. Ralph, E. Blankenship, M. C. Clark, and R. W. Lemke, "Pulse shortening in the magnetically insulated line oscillator," in Proc. SPIE 2843, 1996, pp. 144-152.

[27] K. J. Hendricks, P. D. Coleman, R. W. Lemke, M. J. Arman, and L. Bowers, "The extraction of $1 \mathrm{GW}$ of RF power from an injection locked relativistic klystron oscillator," Phys. Rev. Lett., vol. 76, p. 154, 1996.

[28] K. Ronald, A. W. Cross, A. D. R. Phelps, W. He, H. Yin, and S. N. Spark, "Explosive cathode gyrotron experiments," in Dig. Tech. Papers, Int. Workshop on High Power Microwave Generation and Pulse Shortening, Edinburgh, U.K., June 10-12, 1997, pp. 21-26.

[29] R. B. Miller, "Pulse shortening in high-peak-power reltron tubes," this issue, pp. 340-347.

[30] D. Price, J. S. Levine, and J. Benford, "Diode plasma effects on the microwave pulse length from relativistic magnetrons," in Dig. Tech. Papers, Int. Workshop on High Power Microwave Generation and Pulse Shortening, Edinburgh, U.K., June 10-12, 1997, pp. 127-134.

[31] D. Price and J. N. Benford, "General scaling of pulse shortening in explosive-emission-driven microwave sources," this issue, pp. 256-262.

[32] K. Hendricks, M. Haworth, D. Schiffler, G. Baca, T. Spencer, M. Arman, L. Bowers, K. Hackett, S. Calico, T. Englert, M. Sena, D. Ralph, M. Scott, D. Trujillo, R. Lemke, M. C. Clark, P. D. Coleman, and R. Gallegoes, "Results of research on overcoming pulse shortening of GW class HPM sources," in Dig. Tech. Papers, Int. Workshop on High Power Microwave Generation and Pulse Shortening, Edinburgh, U.K., June 10-12, 1977, pp. 81-90.

[33] K. J. Hendricks, M. D. Hayworth, T. Englert, D. Shiffler, G. Baca, P. D. Coleman, L. Bowers, R. W. Lemke, T. A. Spencer, and M. J. Arman, "Increasing the RF energy per pulse of an RKO," this issue, pp. 320-325.

[34] F. W. Arter and J. Eastwood, "Characterization of relativistic magnetron behavior by 3-D PIC simulation," this issue, pp. 714-725.

[35] R. Kishak and Y. Y. Lau, "Interaction of multipactor discharge and R. F. circuits," Phys. Rev. Lett., vol. 75, p. 1218, 1995.

[36] A. Neuber, J. Dickens, D. Hemmet, H. Krompholz, L. L. Hatfield, and M. Kristiansen, "Window and cavity breakdown caused by high power microwaves," in Dig. Tech. Papers, Int. Workshop on High Power Microwave Generation and Pulse Shortening, Edinburgh, U.K., June 10-12, 1997, pp. 31-35.

[37] R. A. Kishek, Y. Y. Lau, and R. M. Gilgenbach, "Multipactor discharge on a dielectric," in Dig. Tech. Papers, Int. Workshop on High Power Microwave Generation and Pulse Shortening, Edinburgh, U.K., June 10-12, 1997, pp. 27-29.

[38] E. V. Ilyakov, G. S. Korablyov, I. S. Kulagin, and N. I. Zaitsev,
"Relativistic carcinatron with a thermionic injector of electrons," in Dig. Tech. Papers, Int. Workshop on High Power Microwave Generation and Pulse Shortening, Edinburgh, U.K., June 10-12, 1997, pp. 45-48.

[39] T. A. Spencer, K. J. Hendricks, J. W. Luginsland, and M. D. Stump, "Dynamics of the space charge limiting current in gyro-type devices," in Dig. Tech. Papers, Int. Workshop on High Power Microwave Generation and Pulse Shortening, Edinburgh, U.K., June 10-12, 1997, pp. 161- 171.

[40] M. Friedman, R. Fernsler, S. Slinker, R. Hubbard, and M. Lampe, "Efficient conversion of the energy of intense relativistic electron beams into rf waves," Phys. Rev. Lett., vol. 75, p. 1214, 1995.

[41] K. Hendricks, private communication, 1997.

[42] A. V. Gunin, A. I. Klimov, S. D. Korovin, I. K. Kurkan, I. V. Pegel, S. D. Polevin, A. M. Roitman, V. V. Rostov, A. S. Stepchenko, and E. M, Totmenov, "Relativistic X-band BWO with $3 \mathrm{GW}$, output power," this issue, pp. 326-331.

[43] E. B. Abubakirov, A. N. Denisenko, M. I. Fuchs, N. F. Kovalev, E. I. Soluyanov, A. V. Savelyev, V. V. Yastrebov, and J. P. Brasile, "Oversized BWO with selective Bragg mode converter," in Dig. Tech. Papers, Int. Workshop on High Power Microwave Generation and Pulse Shortening, Edinburgh, U.K., June 10-12, 1997, pp. 179-183.

[44] E. Garate, R. McWilliams, K. J. Hendricks, T. A. Spencer, M C. Clark, and A. Fisher, "Novel cathode for field-emission applications," Rev. Sci. Instrum., vol. 66, no. 3, pp. 2528-2532, Mar. 1995.

[45] C. B. Fleddermann and J. A. Nation, "Ferroelectric sources and their application to pulsed power: A review," IEEE Trans. Plasma Sci., vol. 25, pp. 212-220, Apr. 1997

[46] D. Fletchner, Cz. Golkowski, J. D. Ivers, G. S. Kerslick, J. A. Nation, and L. Schachter, "Electron emission and electron gun operation of PZT ferroelectric cathodes," in Dig. Tech. Papers, Int. Workshop on High Power Microwave Generation and Pulse Shortening, Edinburgh, U.K., June 10-12, 1997, pp. 15-19.

[47] S. Bugaev, V. Kavenets, A. Klimov, V. Koshelev, and V. Cherepinin "The interaction of an electron flow and electromagnetic field in a $10^{10}$ W-multiwave Cerenkov generator," Radiotech. Electron., vol. 32, pp. 1488-1498, 1987. (See also [9] for additional references to his work.)

[48] B. Abubakirov, M. I. Fuchs, N. F. Kovalev, "Relativistic TWT with multi-channel nonlinear feedback," Dig. Tech. Papers, Int. Workshop on High Power Microwave Generation and Pulse Shortening, Edinburgh, U.K., June 10-12, 1997, pp. 245-249.

[49] O. T. Loza and P. S. Strelkov, "Microwave pulse shortening in relativistic high-current microwave oscillators," in Dig. Tech. Papers, Int. Workshop on High Power Microwave Generation and Pulse Shortening, Edinburgh, U.K., June 10-12, 1997, pp. 103-108.

[50] E. A. Galstjan and L. N. Kazanskiy, "Using of two-beams cathode for formation of REB with supershort front for high-power MW generators," in Dig. Tech. Papers, Int. Workshop on High Power Microwave Generation and Pulse Shortening, Edinburgh, U.K., June 10-12, 1997, pp. 197-201.

[51] G. Caryotakis, "High power microwave tubes, in the laboratory and on line," IEEE Trans. Plasma Science, vol. 22, pp. 683-691, Oct. 1994.

[52] D. Sprehn, G. Caryotakis, and R. M. Phillips, "150 MW S-band klystron program at the Stanford linear accelerator center," presented at Pulsed RF sources for Linear Colliders Conf., Hayama, Japan, Apr. 8-12, 1996; also SLAC Pub 7232, July 1996.

[53] G. Scheitrum, SLAC, private communication, July 1997.

[54] G. Caryotakis, E. Jongewaard, R. Phillips, G. Schietrum, S. Tantawi, and N. Luhmann, "A 2-gigawatt, 1-microsecond microwave source," in Proc. 11th Int. Conf. on High Power Particle Beams, Beams 96, vol. 1, 1996, pp. 406-409.

[55] M. Friedman and V. Serlin, "Present and future developments of high power relativistic klystron amplifiers," in Proc. SPIE 1629, 1992, pp. $2-7$.

[56] V. Serlin and M. Friedman, "Terawatt electronics," in Proc. EUROEM 94 Int. Symp., Bordeaux, France, May 30-June 3 1994, pp. 103-110, 1995.

[57] K. J. Hendricks, P. D. Coleman, M. D. Haworth, T. A. Spencer, M. J. Arman, and L. Bowers, "Issues for generation of long pulse, intense annular relativistic electron beams for relativistic klystron devices," in Proc. SPIE 2557, 1995, pp. 9-20.

[58] J. W. Louginsland, Y. Y. Lau, K. J. Hendricks, and P. D. Coleman, "A model of injection-locked relativistic klystron oscillator," IEEE Trans. Plasma Sci., vol. 24, pp. 935-937, 1996.

[59] G. Faillon and A. J. Durand "Conventional and therefore reliable vacuum tubes technology extrapolation toward HPM microwave sources," presented at the Int. Workshop on High Power Microwave Generation and Pulse Shortening, Edinburgh, U.K., June 10-12, 1997.

[60] M. D. Hayworth, G. Baca, J. Benford, T. Englert, K. Hackett, K. J. Hendricks, D. Henley, M. LaCour, R. W. Lemke, D. Price, D. Ralph, 
M. Sena, D. Shiffler, and T. A. Spencer, "Significant pulse-lengthening in a multigigawatt magnetically insulated transmission line oscillator," this issue, pp. 312-319.

[61] F. J. Agee and R. J. Barker, "Basic research in high power microwaves (HPM): Recent progress in university and Air Force Research Laboratory efforts," in Proc. SPIE 3158, Intense Microwave Pulses V, 1997, pp. $120-128$

[62] J. W. Eastwood, K. C. Hawkins, and M. P. Hook, "The tapered MILO," this issue, pp. 698-713.

[63] D. K. Abe, S. M. Miller, Y. Carmel, A. Bromborsky, T. M. Antonsen, Jr., B. Levush, and W. W. Destler, "Overmoded backward-wave oscillator: A comparison of experimental results with nonlinear analysis," in Conf. Rec.-Abstracts, 24th IEEE Int. Conf. on Plasma Science, May 19-22, 1997, p. 294.

[64] D. M. Goebel, E. S. Ponti, J. R. Feicht, and R. M. Watkins, "PASOTRONTM high-power microwave source performance," in Proc. SPIE 2843, 1996, pp. 69-78.

[65] C. Grabowski, J. M. Gahl, E. Schamiloglu, and C. B. Fleddermann, "Pulse shortening in high-power backward wave oscillators," in Proc. SPIE 2843, 1996, pp. 251-259.

[66] C. Grabowski, J. M. Gahl, and E. Schamiloglu, "Initial plasma-filled BWO results using a nover cathode mounted plasma injection system," in Dig. Tech. Papers, Int. Workshop on High Power Microwave Generation and Pulse Shortening, Edinburgh, U.K., June 10-12, 1997, pp. $9-14$.

[67] A. K. Shkvarunets, S. Kobayashi, J. Weaver, Y. Carmel, J. Rogers, T. M. Antonsen, Jr., V. L. Granatstein, and W. W. Destler, "Electromagnetic properties of corrugated and smooth filled with radially inhomogenius plasma," IEEE Trans. Plasma Science, vol. 24, pp. 905-917, June 1996.

[68] A. Shkvarunets, S. Kobayashi, Y. Carmel, J. Rodgers, T. M. Antonsen, Jr., and V. L. Granatstein, "Operation of a relativistic backward wave osillator filled with a pre-ionized, high density, radially inhomogeneous plasma," in Dig. Tech. Papers, Int. Workshop on High Power Microwave Generation and Pulse Shortening, Edinburgh, U.K., June 10-12, 1997, pp. 251-282.
[69] F. Hegeler, C. Grabowski, and E. Schamiloglu, "Electron density measurements during microwave generation in a high power backward wave oscillator," this issue, pp. 275-281.

[70] C. Grabowski, J. Gahl, and E. Schamiloglu, "Initial plasma-filled backward wave oscillator experiments using a cathode-mounted plasma prefill source," this issue, pp. 653-668

[71] S. N. Spark, DERA, private communication, Nov. 1997.

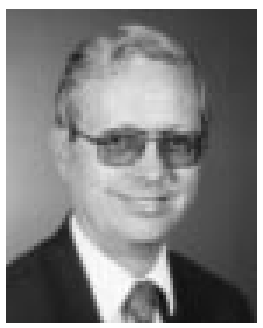

Forrest J. Agee (M'82-SM'91) received the B.S degree from Clemson University, Clemson, SC, in 1963, and the M.S. and Ph.D. degrees in physics from the University of Virginia, Charlottesville, in 1965 and 1967, respectively.

He worked in the acoustics of ship silencing for the U.S. Navy and low temperature physics for the U.S. Army in the 1960's. He worked on nuclear electromagnetic pulse (EMP) hardening and testing from 1971 to 1979 for the Harry Diamond Laboratories and on EMP and strategic communications programs for the BDM Corporation from 1979 to 1982. In 1982, he became the Director of the AURORA Radiation Facility of the Defense Nuclear Agency at Harry Diamond Laboratories. In 1990, he took over the Army High Power Microwave Program and served as Chairman of the Joint Directors of Laboratories Technology Panel on Directed Energy Weapons. In 1993, he moved to the USAF Phillips Laboratory (now the Air Force Research Laboratory) to lead the development of HPM sources. In 1998, he became the Director of Physics and Electronics at the Air Force Office of Scientific Research. He received a U.S. patent for a system for electromagnetic testing of buried conduits that was used by the Army SAFEGUARD ABM System and Polar Telephone Company in North Dakota. His research interests include high-power microwave sources, short pulse transient electromagnetics, pulsed power, and the nuclear physics of spin isomers. 